\title{
Measurement of disease severity in cutaneous autoimmune diseases Cynthia Anyanwu ${ }^{1,2, \#}$, Jamie Langenhan $\mathrm{MD}^{1,2, \#}$ and Victoria P. Werth ${ }^{1,2, *}$
}

\author{
Addresses: ${ }^{1}$ Philadelphia VA Medical Center, Philadelphia, PA; ${ }^{2}$ Department of Dermatology, University of Pennsylvania \\ School of Medicine, Philadelphia, PA \\ \# Cynthia Anyanwu and Jamie Langenhan are co-first authors and made equal contributions \\ * Corresponding author: Victoria P. Werth (werth@mail.med.upenn.edu) \\ FI000Prime Reports 2013, 5:19 (doi:10.12703/P5-19)
}

This is an open-access article distributed under the terms of the Creative Commons Attribution-Non Commercial License (http://creativecommons.org/licenses/by-nc/3.0/legalcode), which permits unrestricted use, distribution, and reproduction in any medium, provided the original work is properly cited. You may not use this work for commercial purposes.

The electronic version of this article is the complete one and can be found at: http://f 1000 .com/prime/reports/m/5/l9

\begin{abstract}
The development of disease-specific outcome instruments for several autoimmune skin diseases including cutaneous lupus erythematosus (CLE), dermatomyositis, vitiligo, pemphigus and alopecia areata has facilitated the objective assessment of disease in clinical trials. Validation of these instruments provides reliable tools to measure disease severity and therapeutic effect in clinical studies. However, the existence of multiple outcome measures for each disease and the lack of uniformity between studies has created a challenge in comparing results across trials. Efforts to address this issue include the Core Outcome Measures in Effectiveness Trials (COMET) initiative and international meetings directed at reaching a consensus. Other challenges with the use of outcome measures include difficulties measuring change in mild disease, measuring response in topical studies, and capturing disease activity in skin with extensive post-inflammatory hyperpigmentation.
\end{abstract}

\section{The importance of outcome measures for cutaneous autoimmune disease}

Until recently, there has been a near-absence of clinical studies in autoimmune skin diseases. The understanding of disease progression and development of novel therapeutic options for cutaneous autoimmune diseases, including CLE, dermatomyositis, morphea, vitiligo, pemphigus, and bullous pemphigoid, is facilitated by the recent development and efforts to validate outcome instruments specific to each of these conditions. Validated disease severity measures allow objective assessment of disease in clinical practice, translational research, and comparative trials. More global measures of disease severity, like those required for studies of systemic lupus erythematosus (SLE) introduce the challenge of capturing improvement in a single-organ system [1]. Skin-specific outcome measures have the potential to more accurately assess the efficacy of skin-directed therapies. Successful development of these measures requires consensus among physicians to prevent a mushrooming of indices, thus facilitating comparison in clinical practice outcomes and clinical trials.
Two systematic reviews noted the use of 25 different outcome measures [2] and 11 different instruments [3] in randomized controlled trials of vitiligo treatments. This lack of uniformity contributes to the challenge of comparing trials and making clinical decisions.

Many aspects of skin disease can be measured, but skinspecific outcome measures need only include the few cutaneous manifestations that are both reliable and characteristic of disease activity. Efforts to reach a consensus on the most appropriate tools to measure cutaneous autoimmune disease have included discussions at the First International Conference on CLE [4], the Rheumatologic Dermatology Society, and the International Pemphigus Committee [5]. A similar exchange of ideas is taking place on a larger scale through the Harmonizing Outcome Measures for Eczema (HOME) [6] and the COMET initiative [7].

The Cutaneous Lupus Erythematosus Disease Area and Severity Index (CLASI) resulted from an iterative process 
among several rheumatologists and dermatologists [8]. Feedback and suggestions were implemented after use of earlier versions by the group [8]. Similarly, the Pemphigus Disease Area Index (PDAI) and Bullous Pemphigoid Disease Area Index (BPDAI) were developed by an international group of bullous disease experts seeking reliable measures to compare outcomes [9].

Features of a reliable clinical outcome measure include credibility, comprehensiveness, sensitivity, accuracy, construct validity, and feasibility [10]. Validation of disease severity measures also requires consideration of inter-rater and intra-rater reliability as well as responsiveness. This process, largely completed with the CLASI $[8,11,12]$, is underway with the Cutaneous Dermatomyositis Disease Area and Severity Index (CDASI) [13-16], the PDAI $[17,18]$ and the Localized Scleroderma Cutaneous Assessment Tool (LoSCAT) $[19,20]$. These instruments distinguish between activity and damage to avoid paradoxical stability in instances when disease activity improves and damage persists. The notion of evaluating skin disease in several anatomic areas rather than approximating percentage of body surface area affected encourages examination of the whole body while optimizing the ability to quantify severity. Other instruments based on measuring surface area may be difficult to use in patients with diseases that frequently involve small surface areas $[13,17]$.

\section{Patient care and the patient perspective}

Given that medical specialists who are not dermatologists care for patients with cutaneous autoimmune conditions, it is desirable that disease-specific outcome measures be readily extended for their use. Krathen et al. evaluated the validity of the CLASI among rheumatologists and found excellent inter- and intra-rater reliability and a strong correlation with CLASI reliability among dermatologists [21]. This study highlights the importance of appropriate attribution of skin findings in order to maintain reproducibility and appropriate use of these tools by physicians of different disciplines.

Validation of the CLASI has made it available for use in studies evaluating the efficacy of various therapeutic options for CLE [11,22-29]. As validated outcome measures become available for other conditions, it is hoped that similar advances will be made, facilitating greater numbers of studies that develop evidence for treatment efficacy.

Autoimmune skin diseases are associated with severely impaired quality of life, as demonstrated in recent studies of CLE and dermatomyositis [30,31]. Several studies have investigated the relationship between quality of life and disease severity in cutaneous autoimmune diseases $[12,32,33]$. While it is important to maintain the separation of physician- and patientderived scores [34], patient-derived outcome measures can contribute to the assessment of overall disease. Patient input may be obtained using visual analogue scales for pain and itch, health related quality of life questionnaires focusing on the skin, such as the Skindex and Dermatology Life Quality Index (DLQI), or on the disease impact overall, with the Short Form 36 (SF-36) and the Health Assessment Questionnaire-Disability Index (HAQ-DI). The Alopecia Areata Quality of Life Index (AA-QLI) is a disease-specific questionnaire developed to evaluate the impact of alopecia areata on quality of life, which was found to have greater specificity [35]. These patient-reported outcomes contribute to the measurement of disease severity in cutaneous autoimmune diseases.

\section{Translation from clinical practice to bench research}

Another relationship, the correlation of clinical response with biomarkers, is becoming an important way to elucidate the molecular pathways that underlie the pathogenesis of cutaneous autoimmune disease and provide an independent and potentially early evaluation of the efficacy of therapy. This past year, Braunstein $e t$ al. demonstrated increased expression of five interferon (INF)-regulated genes in patients with CLE that correlated with cutaneous disease activity, as determined by the CLASI [36]. These results suggest that the presence of an interface dermatitis in specific subtypes of CLE, namely discoid and subacute CLE, likely share some common inflammatory pathways with SLE [36]. Additionally, Oh et al. have shown that INFa and another cytokine, interleukin-17, positively correlate with the CLASI score, indicating the role of INF $\alpha$ in the pathogenesis of CLE [37]. Another study from Nabatian et al. showed positive correlation with tumor necrosis factor (TNF)- $\alpha$ release by cultured peripheral blood mononuclear cells and disease severity in discoid lupus erythematosus, as measured by the CLASI [38]. By understanding the molecular pathways that correlate with clinical manifestation of disease, it may be possible to develop more targeted treatments for cutaneous autoimmune diseases, as well as identify biomarkers that may be used to evaluate disease response to therapy. This new knowledge may also allow mechanistic studies about how current treatments, such as antimalarials, work and why certain patients are refractory to treatment $[39,40]$.

Hitting the floor: disease severity in clinical trials The development and validation of outcome instruments permits objective measurement of disease severity, a necessary feature that allows the results of clinical trials 
to be accurately interpreted and compared. Difficulties have been noted in measuring and validating change in mild cutaneous autoimmune disease and are largely attributed to a statistical concept known as the floor effect [41-43]. Floor effect describes a situation in which the data measured cannot assume a value lower than a particular number, i.e. "the floor" and much of the data is close to this threshold [43]. In other words, mild disease has less room for improvement than severe disease. Thus, measuring change in mild disease with an outcome instrument can be problematic. The Psoriasis Area and Severity Index (PASI) and Psoriasis Disability Index, for example, have both shown significant floor effect $[41,42]$. This necessitates the use of patients with moderate to severe disease in clinical trials to demonstrate efficacy of therapeutic agents [44-46].

\section{New challenges and new approaches}

While much progress has been made in quantifying disease severity in autoimmunity, there are still questions that cannot be easily answered with an outcome instrument. Though focusing on populations with severe and moderate disease in clinical trials avoids negative results due to the floor effect, the problem of effectively and objectively measuring clinically mild disease remains [41-43]. Measurement of disease response using validated outcome instruments in topical studies has also proved difficult, as many outcome measures are inadequate to assess a single lesion or clinical disease that only affects a small area of skin, especially those that use body surface area as a parameter $[13,17,18,47,48]$. Recently, Erceg et al. showed promise for pulsed dye laser therapy in discoid cutaneous lupus erythematosis using the CLASI, but excluding its disease area component, as a validated instrument to measure response in single lesions [23]. Change in disease activity was reflected in the CLASI score [23], indicating that the CLASI may be more sensitive than other external measures, such as visual analogue scale activity or Likert scores, in evaluating mild disease and single lesions. Chang et al. also indicate that the CLASI may be more sensitive in evaluating mild disease in their statistical analysis [43]. However, this is hard to prove without more sensitive gold standards to evaluate mild disease $[43,23]$.

The objective and reliable measurement of erythema in darker skin tones also remains a challenge. Frequently, one can distinguish activity and damage in the same lesion, with erythema determined visually as pinkness or redness in comparison to background skin. However, when hyperpigmentation is marked and overlaps with the erythema it can be difficult to evaluate the erythema [49]. Objective methods have been explored, including use of diffuse reflectance spectroscopy and colorimetry to measure erythema in vivo $[49,50]$. These types of solutions come with their own problems including variables like probe-skin contact and temperature, and appropriate operational training [49]. Some studies have suggested that visual determination of erythema correlates with objective measures [51-53]. Specifically, studies in Japanese subjects suggest that responsiveness can be demonstrated visually [54], but additional studies in dark skin are needed.

In the past few years, great strides have been made in understanding disease progression and developing therapeutic solutions for cutaneous autoimmune diseases through the utilization of validated outcome instruments. Clinical trials and translational research have emerged from the shared efforts of physicians to reach a consensus on the most appropriate tools to assess

Figure I. Hypertrophic lupus erythematosus lesion

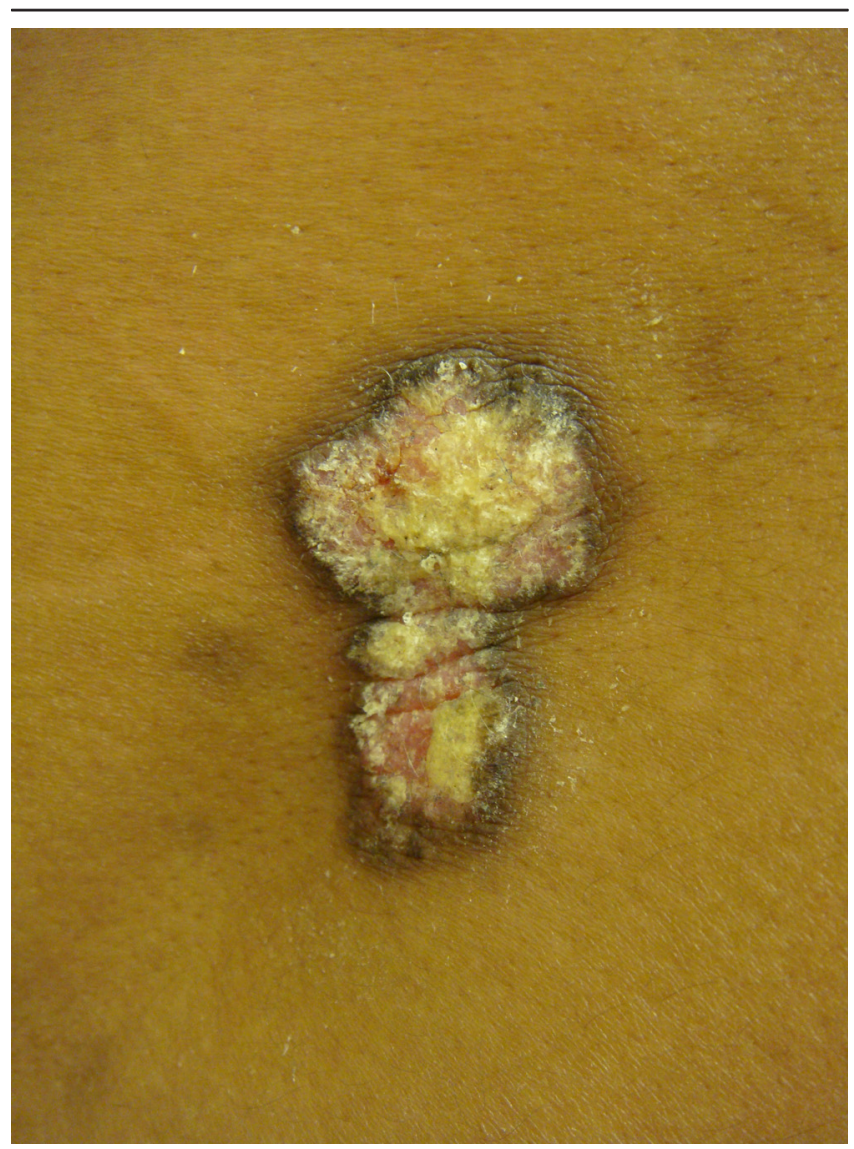

Hypertrophic lupus erythematosus lesion demonstrating features of both activity and damage in the same lesion. There is erythema, scale and hypertrophy, which represent activity as well as hyperpigmentation at the periphery of the lesion, which represents damage. These features can now be captured with a validated disease severity measure. 
cutaneous disease. Though challenges still remain, including assessing mild disease and objectively characterizing erythema, the implementation of outcome instruments has offered a sensitive and accurate way to discuss cutaneous autoimmune diseases over many studies in many disciplines.

\section{Abbreviations}

AA-QLI, Alopecia Areata Quality of Life Index; BPDAI, Bullous Pemphigoid Disease Area Index; CDASI, Cutaneous Dermatomyositis Disease Area and Severity Index; CLASI, Cutaneous Lupus Erythematosus Disease Area and Severity Index; CLE, cutaneous lupus erythematosus; COMET, Core Outcome Measures in Effectiveness Trials; DLQI, Dermatology Life Quality Index; HOME, Harmonizing Outcome Measures for Eczema; INF, interferon; LoSCAT, Localized Scleroderma Cutaneous Assessment Tool; PASI, Psoriasis Area and Severity Index; PDAI, Pemphigus Disease Area Index; SLE, systemic lupus erythematosis; TNF, tumor necrosis factor.

\section{Disclosure}

Victoria Werth developed the CLASI and CDASI, and the copyright is owned by the University of Pennsylvania.

\section{References}

I. Albrecht J, Werth VP: Clinical outcome measures for cutaneous lupus erythematosus. Lupus 2010, 19:1 137-43.

2. Eleftheriadou $V$, Thomas KS, Whitton ME, Batchelor JM, Ravenscroft JC: Which outcomes should we measure in vitiligo? Results of a systematic review and a survey among patients and clinicians on outcomes in vitiligo trials. $\mathrm{Br} J$ Dermatol 2012, 167:804-14.

\section{FlOOOPrime}

\section{RECOMMENDED}

3. Vrijman C, Homan ML, Limpens J, van der Veen W, Wolkerstorfer A, Terwee CB, Spuls PI: Measurement Properties of Outcome Measures for Vitiligo: A Systematic Review. Arch Dermatol 20I2, I-8.

\section{FlOOOPrime}

\section{RECOMMENDED}

4. Kuhn A, Rondinone R, Doria A, Shoenfeld Y: Ist International Conference on Cutaneous Lupus Erythematosus Düsseldorf, Germany, September I-5, 2004. Autoimmun Rev 2005, 4:66-78.

5. Murrell DF, Dick S, Ahmed AR, Amagai M, Barnadas MA, Borradori L, Bystryn J, Cianchini G, Diaz L, Fivenson D, Hall R, Harman KE, Hashimoto T, Hertl M, Hunzelmann N, Iranzo P, Joly P, Jonkman MF, Kitajima Y, Korman NJ, Martin LK, Mimouni D, Pandya AG, Payne AS, Rubenstein D, Shimizu H, Sinha AA, Sirois D, Zillikens D, Werth VP: Consensus statement on definitions of disease, end points, and therapeutic response for pemphigus. J Am Acad Dermatol 2008, 58:1043-6.

6. Harmonising Outcome Measures. [http://www.homeforeczema.org/]

7. Core Outcome Measures in Effectiveness Trials Initiative. [http://www. comet-initiative.org/]

8. Albrecht J, Taylor L, Berlin JA, Dulay S, Ang G, Fakharzadeh S, Kantor J, Kim E, Militello G, McGinnis K, Richardson S, Treat J, Vittorio C, van Voorhees A, Werth VP: The CLASI (Cutaneous Lupus Erythematosus Disease Area and Severity Index): an outcome instrument for cutaneous lupus erythematosus. J Invest Dermatol 2005, I 25:889-94.

9. Murrell DF, Daniel BS, Joly P, Borradori L, Amagai M, Hashimoto T, Caux F, Marinovic B, Sinha AA, Hertl M, Bernard P, Sirois D, Cianchini G, Fairley JA, Jonkman MF, Pandya AG, Rubenstein D, Zillikens D, Payne AS, Woodley D, Zambruno G, Aoki V, Pincelli C, Diaz L, Hall RP, Meurer M, Mascaro JM, Schmidt E, Shimizu H, Zone J, et al.: Definitions and outcome measures for bullous pemphigoid: recommendations by an international panel of experts. J Am Acad Dermatol 2012, 66:479-85.

10. Singer AJ, Thode HC, Hollander JE: Research fundamentals: selection and development of clinical outcome measures. Acad Emerg Med 2000, 7:397-40I.

\section{FlOOOPrime}

II. Bonilla-Martinez ZL, Albrecht J, Troxel AB, Taylor L, Okawa J, Dulay S, Werth VP: The cutaneous lupus erythematosus disease area and severity index: a responsive instrument to measure activity and damage in patients with cutaneous lupus erythematosus. Arch Dermatol 2008, 144:173-80.

12. Klein R, Moghadam-Kia S, LoMonico J, Okawa J, Coley C, Taylor L, Troxel AB, Werth VP: Development of the CLASI as a tool to measure disease severity and responsiveness to therapy in cutaneous lupus erythematosus. Arch Dermatol 20II, 147:203-8.

13. Klein RQ, Bangert CA, Costner M, Connolly MK, Tanikawa A, Okawa J, Rose M, Fakharzadeh SS, Fiorentino D, Lee LA, Sontheimer RD, Taylor L, Troxel AB, Werth VP: Comparison of the reliability and validity of outcome instruments for cutaneous dermatomyositis. Br J Dermatol 2008, 159:887-94.

14. Yassaee M, Fiorentino D, Okawa J, Taylor L, Coley C, Troxel AB, Werth VP: Modification of the cutaneous dermatomyositis disease area and severity index, an outcome instrument. $\mathrm{Br} J$ Dermatol 2010, 162:669-73.

15. Goreshi R, Okawa J, Rose M, Feng R, Lee LA, Hansen CB, Bangert CA, Connolly MK, Davis MD, Callen JP, Fett NM, Fakharzadeh SS, Clarke JT, Werth VP: Evaluation of reliability, validity, and responsiveness of the CDASI and the CAT-BM. J Invest Dermatol 2012, 132: I I 17-24

16. Rider LG, Werth VP, Huber AM, Alexanderson H, Rao AP, Ruperto N, Herbelin L, Barohn R, Isenberg D, Miller FW: Measures of adult and juvenile dermatomyositis, polymyositis, and inclusion body myositis: Physician and Patient/Parent Global Activity, Manual Muscle Testing (MMT), Health Assessment Questionnaire (HAQ)/Childhood Health Assessment Questionnaire (C-HAQ), Childhood Myositis Assessment Scale (CMAS), Myositis Disease Activity Assessment Tool (MDAAT), Disease Activity Score (DAS), Short Form 36 (SF-36), Child Health Questionnaire (CHQ), physician global damage, Myositis Damage Index (MDI), Quantitative Muscle Testing (QMT), Myositis Functional Index-2 (FI-2), Myositis Activities Profile (MAP), Inclusion Body Myositis Functional Rating Scale (IBMFRS), Cutaneous Dermatomyositis Disease Area and Severity Index (CDASI), Cutaneous Assessment Tool (CAT), Dermatomyositis Skin Severity Index (DSSI), Skindex, and Dermatology Life Quality Index (DLQI). Arthritis Care Res (Hoboken) 20II, 63(Suppl II):SI I8-57.

17. Rosenbach M, Murrell DF, Bystryn J, Dulay S, Dick S, Fakharzadeh S, Hall R, Korman NJ, Lin J, Okawa J, Pandya AG, Payne AS, Rose M, Rubenstein D, Woodley D, Vittorio C, Werth BB, Williams EA, Taylor L, Troxel AB, Werth VP: Reliability and convergent validity of two outcome instruments for pemphigus. J Invest Dermatol 2009, 129:2404-10.

\section{FlOOOPrime}

18. Daniel BS, Hertl M, Werth VP, Eming R, Murrell DF: Severity score indexes for blistering diseases. Clin Dermatol 2012, 30:108-13.

19. Arkachaisri T, Vilaiyuk S, Torok KS, Medsger TA: Development and initial validation of the localized scleroderma skin damage 
index and physician global assessment of disease damage: a proof-of-concept study. Rheumatology (Oxford) 2010, 49:373-8I.

\section{FlOOOPrime}

20. Fett N, Werth VP: Update on morphea: part II. Outcome measures and treatment. J Am Acad Dermatol 20II, 64:23I-42; quiz 243-4.

21. Krathen MS, Dunham J, Gaines E, Junkins-Hopkins J, Kim E, Kolasinski SL, Kovarik C, Kwan-Morley J, Okawa J, Propert K, Rogers N, Rose M, Thomas P, Troxel AB, van Voorhees A, Feldt JV, Weber AL, Werth VP: The Cutaneous Lupus Erythematosus Disease Activity and Severity Index: expansion for rheumatology and dermatology. Arthritis Rheum 2008, 59:338-44.

22. Kreuter A, Tomi NS, Weiner SM, Huger M, Altmeyer P, Gambichler T: Mycophenolate sodium for subacute cutaneous lupus erythematosus resistant to standard therapy. $\mathrm{Br} J$ Dermatol 2007, 156:1321-7.

23. Erceg A, Bovenschen HJ, van de Kerkhof PCM, Jong EMJG de, Seyger MMB: Efficacy and safety of pulsed dye laser treatment for cutaneous discoid lupus erythematosus. I Am Acad Dermatol 2009, 60:626-32.

\section{FlOOOPrime} RECOMMENDED

24. Kreuter A, Gaifullina R, Tigges C, Kirschke J, Altmeyer P, Gambichler T: Lupus erythematosus tumidus: response to antimalarial treatment in 36 patients with emphasis on smoking. Arch Dermatol 2009, 145:244-8.

25. Shah A, Albrecht J, Bonilla-Martinez Z, Okawa J, Rose M, Rosenbach M, Werth VP: Lenalidomide for the treatment of resistant discoid lupus erythematosus. Arch Dermatol 2009, 145:303-6.

26. Chang AY, Piette EW, Foering KP, Tenhave TR, Okawa J, Werth VP: Response to antimalarial agents in cutaneous lupus erythematosus: a prospective analysis. Arch Dermatol 20I I, I47:126I-7.

27. Braunstein I, Goodman NG, Rosenbach M, Okawa J, Shah A, Krathen M, Kovarik CL, Luning Prak E, Werth VP: Lenalidomide therapy in treatment-refractory cutaneous lupus erythematosus: histologic and circulating leukocyte profile and potential risk of a systemic lupus flare. J Am Acad Dermatol 2012, 66:57I-82.

28. Cortés-Hernández J, Torres-Salido M, Castro-Marrero J, VilardellTarres M, Ordi-Ros J: Thalidomide in the treatment of refractory cutaneous lupus erythematosus: prognostic factors of clinical outcome. $\mathrm{Br}$ J Dermatol 2012, 166:616-23.

\section{FlOOOPrime} RECOMMENDED

29. Cortés-Hernández J, Avila G, Vilardell-Tarrés M, Ordi-Ros J: Efficacy and safety of lenalidomide for refractory cutaneous lupus erythematosus. Arthritis Res Ther 2012, I4:R265.

\section{FlOOOPrime}

\section{RECOMMENDED}

30. Klein R, Moghadam-Kia S, Taylor L, Coley C, Okawa J, LoMonico J, Chren M, Werth VP: Quality of life in cutaneous lupus erythematosus. J Am Acad Dermatol 20II, 64:849-58.

3I. Goreshi R, Chock M, Foering K, Feng R, Okawa J, Rose M, Fiorentino D, Werth V: Quality of life in dermatomyositis. J Am Acad Dermatol 20II, 65: I107-16.

32. Vasquez R, Wang D, Tran QP, Adams-Huet B, Chren M, Costner MI, Cohen JB, Werth VP, Chong BF: A multicentre, cross-sectional study on quality of life in patients with cutaneous lupus erythematosus. Br J Dermatol 2013, 168:145-53.

33. Chang AY, Ghazi E, Okawa J, Werth VP: Quality of life differences between responders and nonresponders in the treatment of cutaneous lupus erythematosus. JAMA Dermatol 2013, 149:104-6.
34. Finlay AY: Measurement of disease activity and outcome in atopic dermatitis. $\mathrm{Br} J$ Dermatol 1996, I35:509-I5.

\section{FlOOOPrime}

35. Fabbrocini G, Panariello L, Vita V de, Vincenzi C, Lauro C, Nappo D, Ayala F, Tosti A: Quality of life in alopecia areata: a diseasespecific questionnaire.J Eur Acad Dermatol Venereol 2012.

\section{FlOOOPrime}

RECOMMENDED

36. Braunstein I, Klein R, Okawa J, Werth VP: The interferonregulated gene signature is elevated in subacute cutaneous lupus erythematosus and discoid lupus erythematosus and correlates with the cutaneous lupus area and severity index score. $\mathrm{Br}$ J Dermatol 20I2, 166:97I-5.

37. Oh SH, Roh HJ, Kwon JE, Lee SH, Kim JY, Choi HJ, Lim BJ: Expression of interleukin- 17 is correlated with interferon- $\alpha$ expression in cutaneous lesions of lupus erythematosus. Clin Exp Dermatol 20II, 36:5 I2-20.

\section{FlOOOPrime
RECOMMENDED}

38. Nabatian AS, Bashir MM, Wysocka M, Sharma M, Werth VP: Tumor necrosis factor $\alpha$ release in peripheral blood mononuclear cells of cutaneous lupus and dermatomyositis patients. Arthritis Res Ther 2012, I4:RI.

39. Rahman P, Gladman DD, Urowitz MB: Smoking interferes with efficacy of antimalarial therapy in cutaneous lupus. I Rheumatol 1998, 25: I7| 6-9.

40. Dutz J, Werth VP: Cigarette smoking and response to antimalarials in cutaneous lupus erythematosus patients: evolution of a dogma. J Invest Dermatol 201 I, I 3 I:1968-70.

4I. Robinson A, Kardos M, Kimball AB: Physician Global Assessment (PGA) and Psoriasis Area and Severity Index (PASI): why do both? A systematic analysis of randomized controlled trials of biologic agents for moderate to severe plaque psoriasis. J Am Acad Dermatol 2012, 66:369-75.

\section{FlOOOPrime \\ RECOMMENDED}

42. Fernandez-Peñas $P$, Jones-Caballero M, Espallardo O, García-Díez $A$ Comparison of Skindex-29, Dermatology Life Quality Index, Psoriasis Disability Index and Medical Outcome Study Short Form 36 in patients with mild to severe psoriasis. $\mathrm{Br} J$ Dermatol 2012, 166:884-7.

\section{FlOOOPrime} RECOMMENDED

43. Chang C: The limitations in defining clinically meaningful improvement in disease activity in patients with mild CLE [abstract]. J Invest Dermatol 2013.

44. Inzinger M, Weger W, Heschl B, Salmhofer W, Quehenberger F, Wolf $P$ : Methotrexate vs, fumaric acid esters in moderate-tosevere chronic plaque psoriasis: data registry report on the efficacy under daily life conditions. J Eur Acad Dermatol Venereol 2012

45. Papp KA, Reid C, Foley P, Sinclair R, Salinger DH, Williams G, Dong H, Krueger JG, Russell CB, Martin DA: Anti-IL-I7 receptor antibody AMG 827 leads to rapid clinical response in subjects with moderate to severe psoriasis: results from a phase I, randomized, placebo-controlled trial. J Invest Dermatol 2012, 132:2466-9.

46. Woolacott $N$, Hawkins $N$, Mason A, Kainth A, Khadjesari Z, Vergel YB, Misso K, Light K, Chalmers R, Sculpher M, Riemsma R: Etanercept and efalizumab for the treatment of psoriasis: a systematic review. Health Technol Assess 2006, 10: I-233, i-iv.

47. Faust HB, Gonin R, Chuang TY, Lewis CW, Melfi CA, Farmer ER: Reliability testing of the dermatology index of disease severity (DIDS). An index for staging the severity of cutaneous inflammatory disease. Arch Dermatol 1997, 133:1443-8.

48. Williams HC: Is a simple generic index of dermatologic disease severity an attainable goal? Arch Dermatol 1997, 133:145I-2. 
49. Stamatas GN, Zmudzka BZ, Kollias N, Beer JZ: In vivo measurement of skin erythema and pigmentation: new means of implementation of diffuse reflectance spectroscopy with a commercial instrument. Br J Dermatol 2008, I59:683-90.

\section{FlOOOPrime

RECOMMENDED

50. Syed ZU, Hamzavi IH: Photomedicine and phototherapy considerations for patients with skin of color. Photodermatol Photoimmunol Photomed 201I, 27:10-6.

5I. Lahti A, Kopola H, Harila A, Myllylä R, Hannuksela M: Assessment of skin erythema by eye, laser Doppler flowmeter, spectroradiometer, two-channel erythema meter and Minolta chroma meter. Arch Dermatol Res 1993, 285:278-82.
52. Quinn AG, McLelland J, Essex T, Farr PM: Quantification of contact allergic inflammation: a comparison of existing methods with a scanning laser Doppler velocimeter. Acta Derm Venereol 1993, 73:21-5.

53. Ormerod AD, Dwyer CM, Weller R, Cox DH, Price R: A comparison of subjective and objective measures of reduction of psoriasis with the use of ultrasound, reflectance colorimetry, computerized video image analysis, and nitric oxide production. J Am Acad Dermatol 1997, 37:51-7.

54. Yokogawa N, Kato Y, Sugii S, Inada S: Response to hydroxychloroquine in Japanese patients with systemic lupus erythematosus using the cutaneous lupus erythematosus disease area and severity index (CLASI). Mod Rheumatol 20I2, 22:249-55. 